\title{
Digital educational media in foreign language teaching and learning
}

\author{
Svetlana Kodrle ${ }^{1}$, and Anna Savchenko ${ }^{1 *}$ \\ ${ }^{1}$ Kuban State University, 350040, Stavropolskaya str., 149, Krasnodar, Russia
}

\begin{abstract}
The article considers the ways of exploiting digital educational media in foreign language teaching at Kuban State University. The authors propose a comprehensive definition of digital educational media, which is an umbrella term for Internet-based media, computer-based media and mobile media used for educational purposes. The digital educational media exploited in foreign language teaching are classified into narrative, interactive, adaptive, communicative and productive according to the function they fulfil and the learning experience they support. The article outlines effective ways of incorporating podcasting, multimedia presentations, digital storytelling and other Internet-based media in foreign language teaching. The authors demonstrate that the ways modern media are applied in teaching English are determined by the teacher and depend on the learning objectives. The findings indicate that modern media can be effectively exploited for curricular purposes and assist in developing both foreign language skills and general learning skills. The research done shows that integration of media education and foreign language teaching proves to be the most promising innovative educational technology employed in modern universities today.
\end{abstract}

\section{Introduction}

Intensive introduction of new digital technologies and further development of existing information technologies, including media technologies in all spheres of our life caused rapid fundamental changes in education. The National Doctrine of Education of the Russian Federation till 2025 focuses on the introduction of electronic educational tools, modern information, telecommunication and media technologies into the education system, to foster the integration of Russia into developing global information community and to improve the quality, accessibility, efficiency and competitiveness of domestic education.

Studies have shown $[1,2]$ that the rapidly changing socio-cultural situation is another factor, contributing to introducing significant changes in education. The current social situation due to the coronavirus pandemic has posed a serious challenge to the higher education institutions making them organize distance education based on digital technologies.

\footnotetext{
*Corresponding author: bugaeva_anna@inbox.ru
} 
To meet the expectations and needs of the information society the contemporary higher education system is experiencing digital transformation. According to Russian researchers $[3,4]$, the digital transformation of higher education is the integration of digital technologies into education practices of all levels, implying the development of innovative teaching methods exploiting a variety of media technologies: mobile, smart technologies, interactive information technologies and other related Internet-based educational media resources.

The impact of modern media technologies on education has been the subject of many research papers. In his study A. Verbitsky [5], analyzes the challenges the higher education system faces due to implementing digital learning in the era of cybersocialization of society. He highlights that the only way for digitalization of learning to be productive is to be supported by the psycho-pedagogical theory of contextual education.

In line with the theory of contextual education D. Laurillard [6], proposed her "Conversational framework for the effective use of learning technologies". She worked out a functional classification of media and analyzed their contribution to pedagogical processes within the suggested framework. Previous studies have focused on applying Laurillard's classification of educational media to analyze the components of an online teaching process [7], and to evaluate learning effectiveness of museum Web sites [8]. In this paper we suggest that Laurillard's classification of media may be similarly adopted to analyze the educational efficacy of digital media exploited in foreign language teaching.

The aim of the research is to define and analyze digital educational media applied in foreign language teaching and learning and to study the scope of their application at Kuban State University.

\section{Methods}

In our research we applied the following methods: the analysis and synthesis of scientific concepts, content analysis, descriptive method, structural and functional analysis of the results, quantitative and qualitative research.

The following steps have been taken to achieve the aim of our research.

Firstly, we defined and classified digital educational media on the base of different criteria. We gave definitions to terms "digital media" and "modern media" in the educational context; differentiated terms "educational media" and "media education". We considered the functional classification of educational media suggested by D. Laurillard and summarized its main points.

Secondly, we described the application of digital educational media in foreign language teaching at Kuban State University. We refined D. Laurillard's classification of educational media to analyse the effectiveness of digital media in foreign language teaching within her framework.

Finally, to study the students' assessment of digital media contribution to the development of language skills and general skills, we conducted empirical research applying observation, survey, quantitative research.

\section{Results}

\subsection{Definition and classification of digital educational media}

Modern information society cannot exist without steady progress of digital technologies, which involves the increasing influence of media and further introduction of media educational technologies at universities. 
In the educational context today the term media is used and understood as:

- "a channel or system of communication, information;

- an object on which information may be stored [9]".

To clarify the definition of educational media, it is essential to analyse the existing classifications of media based on various criteria.

Applying the historical criterion, media can be divided into: grand-media (a drum, whistle), handwritten media, printed media, electronic media (telegraph, radio, cinema), digital media (web-sites, Internet, messengers), integrated media (those, which combine all kinds of media and create a convergent media environment).

'Digital media' is an umbrella term for Internet-based media, computer-based media and mobile media. The term 'digital technology' refers to a diverse area of media technologies including Internet-based technologies, computer-based technologies and mobile technologies.

With reference to the evolution of their development media can be classified into traditional and modern. All kinds of media that appeared in the traditional analogue culture belong to traditional media. Modern media are those, which evolved in the period of digitalization, cybersocialization of our society. In terms of their evolution, digital media are referred to as modern media. For this reason, the terms 'digital media' and 'modern media' can be used synonymously in the discourse of our paper.

According to their content, media are subdivided into: scientific, social, political, cultural, educational, etc. In pedagogical theory and practice, educational media technology is defined as a technology using media for educational purposes.

The term "educational media" should be distinguished from the term "media education". While educational media are understood as a tool assisting in gaining knowledge and obtaining skills in the scope of a particular curriculum course, media education is an educational process implying 'learning with the media and from the media', aimed at developing media and information literacy; acquiring critical thinking and communication skills [10], facilitating creativity, promoting interpretation and analysis of media texts; fostering self-expression using media technology.

To extend the definition of educational media we suggest using the analytical classification of educational media presented by D. Laurillard [6]. According to the learning experience they provide and the function they fulfil, D. Laurillard identifies five types of educational media: narrative, interactive, communicative, adaptive, and productive.

In the proposed functional classification of educational media, each type of media is described, characterized and related to a certain kind of students' learning experience: narrative media support attending, apprehending; interactive media support investigating, exploring; adaptive media support experimenting, practicing skills; communicative media support discussing, debating; productive media support articulating, modelling, expressing ideas.

Laurillard's classification of educational media is summarized and presented in Table 1. 
Table 1. Laurillard's classification of educational media.

\begin{tabular}{|c|c|c|c|}
\hline Type of media & Characteristics & $\begin{array}{l}\text { Examples of media, } \\
\text { media technologies }\end{array}$ & $\begin{array}{l}\text { Learning } \\
\text { experience }\end{array}$ \\
\hline Narrative media & $\begin{array}{c}\text { Linear presentational } \\
\text { media, non-interactive, } \\
\text { non-computer based }\end{array}$ & $\begin{array}{c}\text { Print, graphics, picture, } \\
\text { image, audiocassette, } \\
\text { CD, DVD } \\
\text { Television, radio, films }\end{array}$ & $\begin{array}{c}\text { Attending, } \\
\text { apprehending a } \\
\text { lesson as a largely } \\
\text { passive recipient } \\
\text { of information }\end{array}$ \\
\hline Interactive media & $\begin{array}{l}\text { Computer-based } \\
\text { presentational media } \\
\text { which allow users to } \\
\text { interact, navigate and } \\
\text { select the content }\end{array}$ & $\begin{array}{l}\text { Hypertext, hypermedia, } \\
\text { multimedia, Web } \\
\text { resources which contain } \\
\text { texts, graphics, video, } \\
\text { audio or any } \\
\text { combination of these }\end{array}$ & $\begin{array}{c}\text { Investigating, } \\
\text { exploring some } \\
\text { relevant resource } \\
\text { when the way of } \\
\text { interaction with } \\
\text { media is } \\
\text { determined by a } \\
\text { student }\end{array}$ \\
\hline Adaptive media & $\begin{array}{l}\text { Computer-based media } \\
\text { that can change their state } \\
\text { in response to the user's } \\
\text { actions. "An adaptive } \\
\text { media is one that uses the } \\
\text { modelling capacity of } \\
\text { computer program to } \\
\text { accept the input from the } \\
\text { user, transform the state of } \\
\text { the model, and display the } \\
\text { resulting output" [6]. }\end{array}$ & $\begin{array}{c}\text { Tutorial programmes, } \\
\text { tutorial simulations, } \\
\text { simulations, virtual } \\
\text { environments, virtual } \\
\text { worlds }\end{array}$ & $\begin{array}{l}\text { Experimenting, } \\
\text { practicing skills }\end{array}$ \\
\hline $\begin{array}{c}\text { Communicative } \\
\text { media }\end{array}$ & $\begin{array}{l}\text { Digital, Internet based } \\
\text { media } \\
\text { Computer / mobile phone } \\
\text { based media enabling } \\
\text { discourse / discussion / } \\
\text { interaction through texts, } \\
\text { graphics, video, audio or } \\
\text { any combination of them }\end{array}$ & $\begin{array}{c}\text { Computer mediated } \\
\text { conferencing, digital } \\
\text { document discussion } \\
\text { environment, video } \\
\text { conferencing, } \\
\text { audioconferencing }\end{array}$ & $\begin{array}{l}\text { Discussing, } \\
\text { debating }\end{array}$ \\
\hline Productive media & $\begin{array}{l}\text { Media enabling students } \\
\text { to media to become an } \\
\text { author / to create } \\
\text { something }\end{array}$ & $\begin{array}{l}\text { Micro worlds, product, } \\
\text { modelling, animation, } \\
\text { word processor }\end{array}$ & $\begin{array}{l}\text { Articulating, } \\
\text { modelling, } \\
\text { expressing ideas }\end{array}$ \\
\hline
\end{tabular}

To sum up, the analysis of previous studies devoted to the definition and classifications of media in the educational context allowed us to propose a comprehensive definition of digital educational media. Our findings show that digital educational media is an umbrella term for Internet-based media, computer-based media and mobile media used for educational purposes. According to their function, digital educational media are classified as narrative, interactive, communicative, adaptive or productive.

\subsection{Modern media exploited in foreign language teaching and learning at Kuban State University}

As we have stated above, the use of modern media, information and digital technologies has become an integral part of teaching foreign languages and developing reading, writing, listening and speaking skills as well as enlarging the vocabulary, improving pronunciation, motivating students and preparing them to use English for cross-cultural communication. 
Further, we will describe the ways teachers take advantage of the learning potential media technologies afford in teaching English as a foreign language.

Prior research shows that $40 \%$ of our communication time is spent listening to others, $35 \%$ is spent talking to others, $16 \%$ is spent reading and $9 \%$ is spent writing. About $57,7 \%$ of learning time is spent listening. In the process of language learning, listening remains the main source of knowledge and an important tool of language practice in class. It also has a positive impact on students' memory, which plays a crucial role in language acquisition. Thus, listening comprehension plays a vital role in developing language competence. As foreign language acquisition occurs in the Russian-speaking environment, it is vitally important to have access to the authentic teaching resources designed by native speakers.

Modern media such as the World Wide Web offer a great variety of resources that can be exploited to develop listening skills at different levels of language mastery. It allows to apply individual approach to language teaching and to design multi-level tasks for in-class and out-of-class activities. We widely use a number of audio and video resources, such as Businessenglishsite.com, engvid.com, etc. The former provides free audio and video lessons aimed at improving students' listening skills and pronunciation, learning new vocabulary and becoming fluent in the language of business. The latter is a bank of free video lessons lasting for about 30 minutes. The topics of the video lessons for advanced or intermediate learners range from culture tips to ZOOM meeting tips, while the lessons for beginners are mostly devoted to matters relevant to the initial stage of language learning such as most frequently used verbs, prepositions of time, etc. Both resources allow us to apply individual approach to teaching as they provide the tools to customize teaching materials for learners of different levels. The sites mentioned here are just two examples of the numerous Internet resources that are easily adapted to students learning needs.

We assume that one of the most helpful teaching tools based on modern media is podcasts. As a rule, podcasts are devoted to a certain topic and are updated on a regular basis. These audio files can be listened to on a PC or they can be downloaded on a smartphone. Podcasting has evolved greatly since its emergence in 2004 and now these files can be both listened to and watched online. This technology offers great opportunities for foreign language learners, mobile learning being one of them. Further, we will outline how it can be used as an educational medium.

BusinessEnglishPod.com provides free weekly lessons and audio courses for intermediate and advanced learners of English. As the name of the site implies, the materials posted are related to business communication. Each Business English podcast lesson focuses on a particular workplace English skill or situation (meetings, presentations, telephoning, negotiating, socializing, travel, conversation, video conferencing, adapting to change, etc.) and language function (clarifying, disagreeing, questioning, expressing opinions, persuasion etc.). The list of topics is numerous and the teacher can easily choose those their students will most benefit from. As each lesson lasts for about 40 minutes, we consider it reasonable to use this resource for students' independent work that is checked by means of class or group discussions and/or vocabulary revision or test. It is worth mentioning that dialogues and conversations recorded in these lessons can serve templates for role-playing activities.

Scholars claim that significant learning occurs outside formal educational, training or work settings [12]. It makes mobile learning, i.e. learning accomplished with the use of mobile devices and informal learning, i.e. "learning that takes place elsewhere voluntarily and primarily for pleasure" [12] central to meeting the learning needs of the younger generation. For this reason, any authentic feature and documentary films (Learning English Video Project on Englishclub.com, BBC), series ("Friends"), songs, smartphone applications (Duolingo, British Council) are an invaluable source of new knowledge about the language in general and a helping hand in developing listening skills in particular. 
It is obvious that learners learn through conversation with the external world, with themselves, and with other learners and teachers. Therefore, for successful foreign language learning it is essential to create favourable conditions for communication in the classroom. Creating such a stimulating environment became an urgent task that required taking immediate action in March 2020 when higher educational institutions had to work distantly due to the outbreak of COVID 19 pandemic. Kuban State University chose Microsoft Teams platform to conduct practical classes and read lectures. As a result, traditional faceto-face teaching and learning activities had to be converted to the mode of video conferencing. One of the most common complaints voiced by the foreign language teaching community with regard to e-learning is the lack of regular, face-to-face teacher-student and peer interaction [13]. This problem was partly solved by creating separate channels for pairs or groups of students to facilitate simultaneous pair or group work aimed at discussing or debating some issues. This approach was applied when a group discussion was a separate task (e.g. following some text/article or a role playing exercise) and when it was one of the stages of a big project. In some cases, students were asked to record their conversations for further feedback and peer/teacher assessment.

The benefits of applying the principle of peer learning to foreign language teaching have been discussed by K. Voloshina and A. Bolshak [14]. One of the ways to implement this idea using modern digital media is to invite graduates to the virtual classroom to share their experience with undergraduate students. We follow this approach at the Department of Foreign Languages for Professional Communication at Kuban State University. In fact, this 3,5-year training programme is an additional course students can do simultaneously with their first degree. At the end of the course the students have to translate an authentic English text into Russian, analyse the lexical, grammatical and stylistic aspects of the translation and present the work done. The text has to be scientific and relevant to the students' major subject at university. At the beginning of the academic year, we invited our former students to join our online lesson to show multimedia presentations of their projects to graduate students who were going to do the same kind of assignment at the end of the term. Similarly, when translation practice was ending, graduate students presented their projects to junior students who were going to do a similar task next year. In both cases, the presentations were followed by questions and answers sessions, which stimulated online discussion of the points related to the subject of the paper and the translation, as well as some technical issues such as finding the right text, approaches to the task assigned, etc. Thus, students of three different years of study participated in this activity. This experience was beneficial for all the parties involved, it promoted collaborative and cooperative on-line learning and made the participants speak English for a practical purpose.

Multimedia presentations have long been used in teaching foreign languages, both by teachers and students. There are enough tools to create slides (PowerPoint, Bookdown, Office Mix, Prezi, Sway), images or graphs that can be effectively exploited to the mutual benefit of the teaching staff and students. A more sophisticated way to present information or produce a hypertext in a foreign language is digital storytelling, which combines the art of storytelling with the use of various digital devices, services, programmes, graphics, texts, video, audio, etc. There are different types of storytelling (socio-cultural, business, academic, personal, family) and a great number of websites that post digital stories devoted to a wide range of topics. The variety of choices contributes greatly to the didactic potential of this multimedia in foreign language teaching. Apart from using digital storytelling as a source of relevant information presented in an engaging way, in our practical classes digital storytelling is assigned as individual or group project facilitating interaction, cognitive, communication, research and foreign language competence. Thus, the focus is shifted from reproducing the information to competency-based education and creativity. Digital stories can be created in mobile applications and on websites ("UtellStory", "Renderforest", 
spark.adobe), using different programmes («Pivot», «Adobe animation», «Autodesk Maya») or mobile applications («Explain Everything», «Prisma 3D», «FlipaClip»).

When it comes to developing reading skills, new media also offer numerous opportunities. Visiting websites of the leading English/American newspapers or professional journals, reading and rendering articles has become a routine activity of our students. In teaching English for specific or academic purposes, social media (Facebook, Twitter, YouTube) can also be exploited as a resource for sharing and finding articles, studies, new trends and best practices. The reliability of such sources is explained by the fact that the members of professional or scientific communities read and review the information posted on social media. As "digital natives", i.e. those in the 18-34 age range, access one or two social media platforms several times a day [15], social media prove to be an effective teaching tool.

We adopted D. Laurillard's taxonomy (Table 1) to study a wide range of digital media exploited in foreign language teaching at our university. To expand the scope of the analysis, we also researched how media of different types contribute to meeting language learning objectives and general learning objectives. Our findings are summarized in Table 2 .

Table 2. The influence of the types of media on the meeting language learning objectives and general learning objectives.

\begin{tabular}{|c|c|c|c|}
\hline $\begin{array}{c}\text { Type of media/ } \\
\text { learning } \\
\text { experience }\end{array}$ & $\begin{array}{l}\text { Media, methods and } \\
\text { technologies }\end{array}$ & $\begin{array}{l}\text { Language learning } \\
\text { objectives }\end{array}$ & General learning objectives \\
\hline $\begin{array}{l}\text { Narrative } \\
\text { media/ } \\
\text { attending, } \\
\text { apprehending }\end{array}$ & $\begin{array}{l}\text { Texts / articles, graphics, } \\
\text { images, presentations, CD, } \\
\text { DVD, television, radio, } \\
\text { feature / documentary } \\
\text { films }\end{array}$ & $\begin{array}{l}\text { Developing listening / } \\
\text { reading comprehension } \\
\text { skills; vocabulary } \\
\text { development }\end{array}$ & $\begin{array}{l}\text { Promoting open-mindedness and } \\
\text { a positive attitude to other } \\
\text { cultures and better understanding } \\
\text { of students' own cultural } \\
\text { identity; activating visual } \\
\text { memory and imagination; }\end{array}$ \\
\hline $\begin{array}{l}\text { Interactive } \\
\text { media/ } \\
\text { investigating, } \\
\text { exploring }\end{array}$ & $\begin{array}{l}\text { Multimedia presentations, } \\
\text { search engines, on-line } \\
\text { translators, on-line } \\
\text { dictionaries, multiple } \\
\text { choice tests, Web } \\
\text { resources, newspaper } \\
\text { websites, on-line journals, } \\
\text { digital stories, social } \\
\text { media, mobile applications }\end{array}$ & $\begin{array}{l}\text { Reading / listening/ } \\
\text { speaking; } \\
\text { familiarizing with } \\
\text { different functional } \\
\text { styles; vocabulary } \\
\text { development }\end{array}$ & $\begin{array}{l}\text { Exploring, finding, classifying, } \\
\text { selecting relevant information; } \\
\text { understanding, } \\
\text { evaluating, analyzing media } \\
\text { texts; developing computer skills }\end{array}$ \\
\hline $\begin{array}{l}\text { Communicative } \\
\text { media/ } \\
\text { discussing, } \\
\text { debating }\end{array}$ & $\begin{array}{l}\text { On-line conferencing, } \\
\text { discussion forum, email, } \\
\text { mobile applications, } \\
\text { messengers, social media / } \\
\text { social networks, } \\
\text { educational platforms }\end{array}$ & $\begin{array}{l}\text { Listening/ speaking/ } \\
\text { writing; } \\
\text { overcoming the } \\
\text { language barrier; } \\
\text { vocabulary } \\
\text { development; } \\
\text { conversing; discussing; } \\
\text { debating; functional } \\
\text { language }\end{array}$ & $\begin{array}{l}\text { Enhancing communication skills; } \\
\text { explaining information; using } \\
\text { information in new situations; } \\
\text { expressing and interpreting } \\
\text { ideas; drawing connections } \\
\text { between ideas, justifying a stand } \\
\text { or decision; interacting; } \\
\text { brainstorming; critical thinking; } \\
\text { developing media skills }\end{array}$ \\
\hline $\begin{array}{l}\text { Productive } \\
\text { media/ } \\
\text { synthesis of } \\
\text { some new } \\
\text { product }\end{array}$ & $\begin{array}{l}\text { Computer/mobile based } \\
\text { applications for } \\
\text { multimedia presentations } \\
\text { and digital storytelling }\end{array}$ & $\begin{array}{l}\text { Reading/ listening/ } \\
\text { speaking/ writing; } \\
\text { giving a speech; } \\
\text { discussing; making a } \\
\text { presentation; writing } \\
\text { reports, articles, } \\
\text { messages, essays, } \\
\text { formal/ informal letters; } \\
\text { digital storytelling }\end{array}$ & $\begin{array}{l}\text { Creativity, speaking in public, } \\
\text { ability to work independently } \\
\text { and in a team; } \\
\text { setting goals, planning, self- } \\
\text { efficacy, reflection; creating a } \\
\text { media product, media literacy, } \\
\text { digital literacy, editing }\end{array}$ \\
\hline
\end{tabular}

Virtually all types of modern educational media incorporated in foreign language teaching enhance communicative competence (linguistic, sociolinguistic, pragmatic), add to 
cultural awareness, foster communication and support particular kinds of thinking (critical, logical, creative, visual, and intuitive). Therefore, these general learning objectives were not included in Table 2.

The study reveals that the same medium can belong to different types of media depending on the function it fulfils. Accordingly, the same medium can facilitate different learning experience depending on the way it is used. Thus a multimedia presentation shown in the classroom to present some new information is a "narrative" medium as it is just a means to "re-purpose material originally developed for narrative media" [8]. However, when the same presentation is accessed via the Internet, it becomes an "interactive" medium. Finally, if creating a multimedia presentation is supposed to be the final stage of a student's project, it is a "productive" medium. The same refers to digital stories. When used as a way to narrate, digital storytelling proves to be "exploratory" and "interactive" as the students can select which parts they wish to read or to skip, whether they will watch the video once or twice, etc. and "productive" when assigned as a creative task/project. Another example is social media such as Twitter or Facebook exploited to gain new knowledge from written texts or video lectures posted by members of a professional virtual community. In this case, they are "interactive" media. On the other hand, when students express their own ideas in the form of articles or blogs in a foreign language on social networking sites, they use these media as "communicative" and "productive".

Understandably, the function modern media perform and the way they are applied in teaching English are determined by the teacher and depend on the learning objectives. We agree with Stephen Brown who states that for the new medium to reach its pedagogical potential, it is often necessary to reconstruct the learning objectives [7]. We argue that, when it comes to teaching foreign languages, the focus should be on authenticity (reading and listening to authentic materials), research (exploring relevant sources of information on the internet), communication (exchanging opinions and sharing experience via social media or educational platforms), interaction (participating in class or group projects), innovation (looking for new ways of teaching/learning), collaboration (on-line peer and cross-module learning), creativity (producing one's own unique product in a foreign language).

\subsection{Students' evaluation of contribution of digital media to language and general skills development}

In order to study the students' evaluation of digital media effectiveness in language and general skills development, we carried out a survey with the 242 Bachelor students of Kuban State University participating in it. The study involved first year students $(58 \%)$ and second year students (42\%) of Humanities (47\%) and Natural Sciences $(53 \%)$. In our research we employed observation, survey, quantitative research.

We used a questionnaire that contained two multiple-choice questions. The respondents had to assess the effectiveness of modern media in terms of achieving language-learning objectives and general learning objectives as very effective, effective, fairly effective, slightly effective, ineffective. The analysis of the results obtained shows that the vast majority of the respondents consider modern media to be very effective $(53 \%)$ or effective (41\%) for developing foreign language skills, while $6 \%$ consider modern media fairly effective for developing foreign language skills. The results are graphically presented in Fig. 1. 


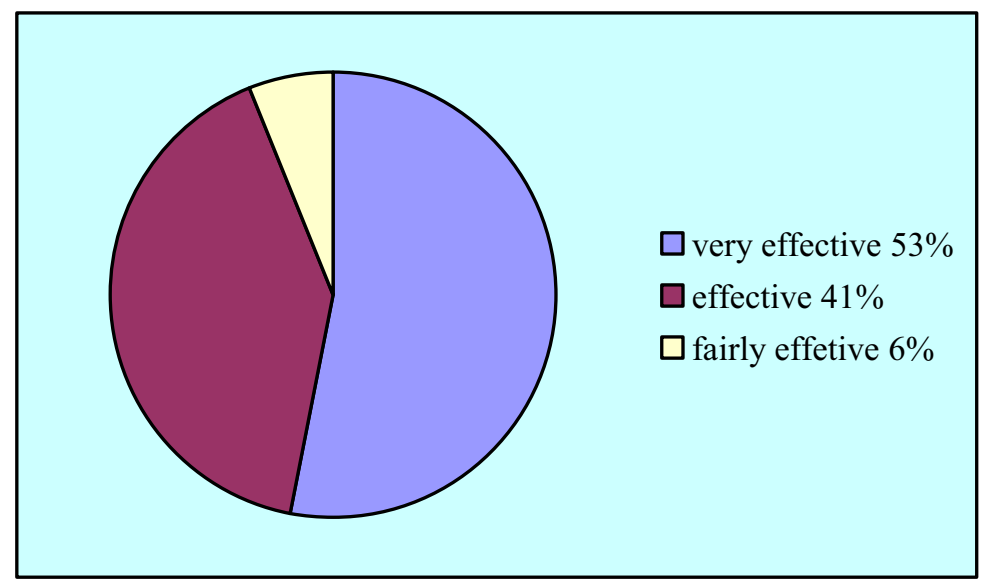

Fig.1.Graph on students' assessment of the effectiveness of modern media for achieving foreign language learning objectives.

When asked how effective modern media exploited in foreign language teachinglearning are for achieving general learning objectives, $36 \%$ of the participants assessed them as very effective, $41 \%$ assessed them as effective, $19 \%$ considered modern media fairly effective, $2 \%$ considered modern media slightly effective and $2 \%$ ineffective. The results are graphically presented in Fig. 2.

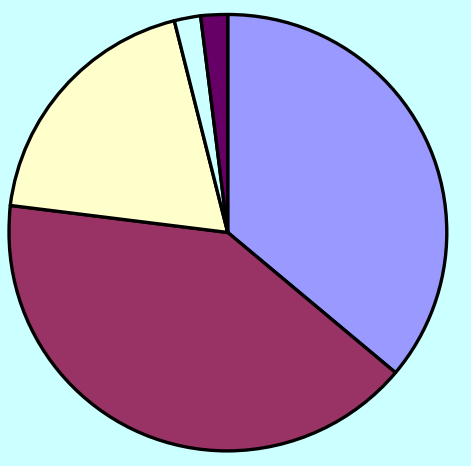

$\square$ very effective $36 \%$

$\square$ effective $41 \%$

$\square$ fairly effective $19 \%$

$\square$ slightly effective $2 \%$

$\square$ ineffective $2 \%$

Fig. 2. Graph on students' assessment of the effectiveness of modern media for achieving general learning objectives.

The data obtained in the survey confirm that students generally perceive modern media as an effective tool for foreign language acquisition. Most respondents also believe that modern media foster general skills development. However, a small percentage of the participants reported modern media exploited in foreign language teaching and learning to be ineffective for achieving general learning objectives. It might indicate that when involved in media-related activity in and out of class, the students' focus is primarily on the language-related tasks. 


\section{Discussion}

At the beginning of this paper we proposed that D. Laurillard's classification of educational media could be adopted to analyze the efficacy of digital educational media in foreign language teaching. The research results have proven this proposition.

Applying the adopted classification, we studied the framework of modern educational media exploited in foreign language teaching at Kuban State University. We analysed the educational efficacy of the digital media and classified them into four types, according to their function and contribution to the students' learning experience, as narrative, interactive, communicative and productive.

The suggested analytical classification demonstrates the direct relation between the type of media used and the certain learning mode: narrative media facilitate learning through acquisition, interactive media promote learning by discovery, adaptive media provide 'guided discovery', communicative media foster learning through discussion, productive media encourage learning through designing a new product.

To expand the scope of the analysis we refined D. Laurillard's classification bringing two more aspects into its framework, namely the contribution of digital educational media exploited in foreign language teaching to achieving language learning objectives and general learning objectives.

The approach adopted in this paper is of theoretical and practical significance. We managed to give an analytical classification of all types of media integrated in foreign language teaching and to relate each of them not only to the certain learning experience of the students, but also to a particular set of language learning objectives and general learning objectives. We consider our research of practical significance as it can be used by foreign language teachers when planning their courses, setting teaching objectives, designing media-based tasks for in-class activities and independent work of students.

The study of educational media applied in foreign language teaching indicates that narrative, interactive, communicative, productive types of media are effectively incorporated into foreign language teaching at Kuban State University, providing students with diversified learning experience. However, adaptive media are not exploited in foreign language teaching due to the lack of appropriate educational media in our educational environment. Therefore, to exploit the teaching potential of adaptive media, it is vitally important for universities to find technical solutions enabling to design simulations and virtual environments for foreign language courses.

In our research we proposed a comprehensive definition of digital educational media and analyzed terms "educational media" and "media education" in the context of foreign language teaching. Our findings show that when incorporated in foreign language teaching, media are not only an efficient educational tool, developing 4 basic language skills (reading, writing, listening and speaking), but also a basis for effective media education, which constitutes a significant part of general learning objectives associated with digital media application.

This conclusion has been confirmed by the survey, conducted to study the students' assessment of digital media effectiveness for the development of language skills and general skills. The results of the survey clearly demonstrate that most students highly assess the educational potential of modern digital media in enhancing both kinds of skills.

To sum up, integration of media education and foreign language learning proves to be the most promising innovative educational technology employed in modern universities today. Developing and reinforcing each other, media education and foreign language learning form a powerful way to create richer learning experiences for students. 


\section{References}

1. I. Abakumova, G. Zvezdina, A. Grishina, et al., E3S Web of Conf., 210, 18017 (2020), doi:10.1051/e3sconf/202021018017

2. T. Shkil, T. Belikova, E3S Web of Conf., 210, 18008 (2020), doi:10.1051/e3sconf/202021018008

3. G. Radchenko, S. Pervukhina, E3S Web of Conf., 210, 18036 (2020), https://doi.org/10.1051/e3sconf/202021018036

4. O. Usacheva, M. Chernyakov, Higher Education in Russia, 5(29), 53-62 (2020), doi:10.31992/0869-3617-2020-29-5-53-62 [CrossRef] [Google Scholar]

5. A. Verbitsky, Homo Cyberus, 1(6) (2019), http://journal.homocyberus.ru/Verbitskiy_AA_1_2019

6. D. Laurillard, Rethinking University Teaching: A Conversational Framework for the Effective Use of Learning Technologies (2013), https://doi.org/10.4324/9781315012940

7. S. Brown, I. Cruickshank, Pedagogical Re-engineering: Using Laurillard's Taxonomy of Educational Media to Guide Curriculum Design (2003)

8. S. Brown, International Journal of Heritage Studies, 12(5), 412-426 (2006), doi: $10.1080 / 13527250600821571$

9. W. M. Chan, K. N. Chin, M. Nagami, T. Suthiwan, Media in Foreign Language Teaching and Learning (SSFLE, 2011)

10. R. Al-Zou'bi, Thinking Skills and Creativity, 39 (2021), doi: https://doi.org/10.1016/j.tsc.2020.100782

11. D. Laurillard, British Journal of Educational Technology, 26(3), 179-189 (2006), doi: 10.1111/j.1467535.1995.tb00340.x

12. J. Quinn, Policy Futures in Education, 16(2), 144-155 (2017), doi: $10.1177 / 1478210317736223$

13. E. Radchenko, M. Kozin, G. Pyrchenkova, E3S Web Conf., 210, 02004 (2020), doi: https://doi.org/10.1051/e3sconf/202021002004

14. A. Bolshak, K. Voloshina, E3S Web Conf., 210, 18013 (2020), doi: https://doi.org/10.1051/e3sconf/202021018013

15. M. M. Abdulqader, Y. Z. Almunsour, Journal of Information \& Knowledge Management, 19(1), 2040023 (2020), https://doi.org/10.1142/S0219649220400237 